\title{
Is use of hospital services a proxy for morbidity? A small area comparison of the prevalence of arthritis, depression, dyspepsia, obesity, and respiratory disease with inpatient admission rates for these disorders in England
}

\author{
J N Payne, J Coy, S Patterson, P C Milner
}

\begin{abstract}
Objectives - To examine the relationship between specific types of morbidity, measured by validated survey questions, and hospital service use and mortality to see if the latter two could act as a proxy in health needs assessment, health service planning, and resource allocation in a typical health district.

Design - A postal questionnaire was used to provide information about depression, digestive disorders, musculo-skeletal disorders, obesity, respiratory disease, and hip and knee pain. The questions were from survey instruments that have been widely used to derive information about these conditions. The relationships between the prevalence of these specific types of morbidity and appropriate admission and mortality rates were explored using linear regression and Pearson correlation analysis.
\end{abstract}

Setting - The population of Rotherham health district, England.

Subjects - A simple random sample of the residents of each of the 22 electoral wards in Rotherham health district.

Results - Responses were obtained from $78 \%$ of the 5000 sampled $(82 \%$ after excluding people who had moved house or died). Significant, positive correlations were found between the prevalence of respiratory disease and the hospital admission and mortality rates for respiratory problems $(r=0.68, p<0.01$ and $\mathbf{r}=0.54, p<0.01$ ) and the prevalence of depression and the admission rate for depression $(r=0.52, p<0.05)$. No such relations were found for digestive disease, musculo-skeletal disease, and obesity. For the conditions examined here, hospital service use was a more useful measure than mortality.

Conclusions - Only two diseases (respiratory disease and depression) out of the seven diseases or procedures investigated showed a positive correlation between hospital admission and disease prevalence. But even for these two, the correlations explained less than $50 \%$ of the variance. Caution must be exercised when hospital service use is being considered as a proxy for morbidity.

\section{( $\mathcal{F}$ Epidemiol Community Health 1994;48:74-78)}

In order to plan for health service developments, health authorities require as accurate an assessment of the health needs of their local populations as possible. ${ }^{12}$ Routine information on health, however, is often inaccurate and may be incomplete and insufficiently comprehensive. ${ }^{23}$ Death certification, which provides a better source of data, is frequently used, ${ }^{4}$ but such mortality data may be inadequate or inappropriate for deploying health service resources more rationally and equitably. ${ }^{56}$ This is especially true for conditions which give rise to substantial amounts of ill health but only rarely to death. Hospital inpatient service use is another very widely used information source. It has the disadvantage, however, that there may be many who could benefit from health services but, because they are not currently receiving them, are consequently not represented. ${ }^{5}$ In spite of these disadvantages, use of hospital services is frequently suggested as a proxy measure ${ }^{7}$ and, indeed, resources are often distributed on this basis.

In measuring the health of whole populations, direct-mailed questionnaires have frequently been used. ${ }^{8}$ Their advantages are that they are a relatively cheap mode of investigation which go a long way towards removing subjectivity. It is important, however, to remember that the results of such surveys are reliable only when relatively high response rates are achieved. ${ }^{8}$

Many survey based studies, and their associated questionnaires, such as the Nottingham Health Profile, ${ }^{910}$ are designed only to give a global picture of an individual's health. Accordingly, the aim of the present study was to compare information from a survey based on well validated questions on specific areas of morbidity with hospital service use and with mortality statistics. We chose, therefore, to explore individual areas of major rnorbidity where routine information is difficult to interpret. These were: depression, digestive disorders, musculo-skeletal disorders, obesity, respiratory disease and, specifically, hip and knee pain. They were picked because for each of them there were validated direct-mailed questions and comparable survey results from other communities available. 
Table 1 The number and source of the questions used in the postal questionnaire.

\begin{tabular}{|c|c|c|}
\hline Clinical area & No of questions & Source \\
\hline $\begin{array}{l}\text { Depression } \\
\text { Digestive disorders } \\
\text { Musculo-skeletal disorders } \\
\text { and hip and knee pain }\end{array}$ & $\begin{array}{l}7 \\
4 \\
4\end{array}$ & $\begin{array}{l}\text { The Hospital Anxiety and Depression Scale }{ }^{12} \\
\text { Postal questionnaire on dyspepsia }{ }^{13} \\
\text { Arthritis and Rheumatism Council: } \\
\text { Epidemiology Research Unit Questionnaire } \\
\text { (Silman, personal communication) }\end{array}$ \\
\hline $\begin{array}{l}\text { Obesity } \\
\text { Respiratory disease }\end{array}$ & $\begin{array}{r}4 \\
10\end{array}$ & $\begin{array}{l}\text { Postal questionnaire on sports injuries }{ }^{14} \\
\text { Medical Research Council's Committee on } \\
\text { Environmental and Occupational Health: } \\
\text { Questionnaire on respiratory symptoms }{ }^{15}\end{array}$ \\
\hline Total & 29 & \\
\hline
\end{tabular}

In a single health district people from different areas within its boundary often have noticeably different levels of health. ${ }^{11}$ However, they all usually have the same hospital services available to them. In planning equitable health care provision we, therefore, need to know whether hospital service use is greatest in those areas in which morbidity is the highest. This paper examines this question and seeks to test the hypothesis that routinely collected hospital activity data can act as a proxy for morbidity in health needs assessment, service planning, and resource allocation in a typical health district.

\section{Methods}

SETTING

Rotherham District Health Authority is coterminous not only with the metropolitan council but also with the family health services authority boundaries. It has an estimated population of 255000 , with 196000 on the electoral roll. There are 22 electoral wards with a mean number of 9000 on the electoral roll, but this ranges from 6000 to 13000 .

\section{SAMPLING PROCEDURE FOR THE MORBIDITY SURVEY}

The sampling frame was the 1990 electoral roll for Rotherham Metropolitan Council. The total sample size was 5000 , and a simple random sample, proportional to the population of each ward, was taken for each of the 22 electoral wards. The questionnaire and the directmail method were piloted on 600 respondents. A response rate of $80 \%$ was achieved after one reminder and the results of the pilot were included with those of the full survey. For the purpose of describing local differences in the prevalence of conditions, the electoral wards were grouped into nine larger localities. Each was a recognised local community as well as being compatible with social service and community unit areas.

Power calculations based on standard statistical assumptions show that a population

Table 2 ICD $9^{16}$ and OPCS $-4^{17}$ codes used to define hospital use for the conditions studied.

\begin{tabular}{ll}
\hline Condition & ICD9 or OPCS-4 codes \\
\hline Depression & ICD9: 296.1, 296.3, 298.0, 300.4, 309.1, 311 \\
Digestive disease & ICD9: 150-151, 157, 530-537 \\
Musculo-skeletal disorders & ICD9: 710-739 \\
Obesity & ICD9: 278 \\
Respiratory disease & ICD9: 162, 490-496 \\
Hip replacements & OPCS-4: W37-W39 \\
Knee replacements & OPCS-4: W40-W42 \\
\hline
\end{tabular}

survey based on the size of these localities (around 430 responses per locality) will estimate a prevalence of $10 \%$ with a $95 \%$ confidence interval of $7 \cdot 25 \%, 12.75 \%$. In analysing correlations between routine data and the prevalence of conditions, however, the estimates of prevalence for individual electoral wards were used. Not only were differences in prevalence greater between wards than between localities, but also the use of ward based estimates ensured that the correlation analysis made maximum use of the information available. Any loss of accuracy in estimating the correlation coefficients because there were smaller numbers in the ward samples was compensated for by the increase in the number of correlation pairs available.

\section{QUESTIONNAIRE}

The questionnaire was set out on four sides of A4 sized paper (an A3 sheet folded in half). It covered five clinical areas in which routine information on morbidity is lacking: depression, digestive disorders, musculo-skeletal disorders, obesity, respiratory disease, and, specifically, hip and knee pain. The number of questions in each area and their sources are shown in table 1 .

The questionnaire was designed so that the questions could be considered in simple consecutive order and it could be easily completed. Envelopes were addressed to named people on the electoral roll and the name was also used to address the person on the covering letter. These letters were on health authority headed notepaper and signed by the director of public health. The survey was carried out in February 1991, and the questionnaires were posted on a Thursday so that they could be completed over the weekend. A reply paid envelope was used for the first mailing, and a stamped addressed envelope for the reminder. Press releases were sent at the time of the survey to all local media, members of parliament, general practitioners, and local councillors.

\section{HOSPITAL USE AND MORTALITY DATA}

Hospital admissions were measured as consultant episodes for relevant primary and other diagnoses or procedures. Numbers of episodes for hospitals within the Trent health region were obtained by electoral ward of residence from the regional patient information system. These data were derived from Körner returns for the period covering the five financial years $1987 / 8-1991 / 2$. The ICD ${ }^{16}$ or OPCS $-4^{17}$ codes that were used to define depression, digestive disease, musculo-skeletal disorders, obesity, respiratory disease and major joint replacements are shown in table 2 . Relevant mortality data were also obtained from OPCS death tapes for the same period.

\section{ANALYSIS}

The responses to the survey questions were translated into assessments of morbidity. The definitions of these are listed below: 
Table 3 The variation in the prevalence of different morbidities by age and sex.

\begin{tabular}{|c|c|c|c|c|c|c|c|c|}
\hline & \multicolumn{6}{|c|}{ Age (y) } & \multicolumn{2}{|c|}{ All ages } \\
\hline & \multicolumn{2}{|c|}{$18-34$} & \multicolumn{2}{|c|}{$35-54$} & \multicolumn{2}{|l|}{$55+$} & \multirow[b]{2}{*}{ Men } & \multirow[b]{2}{*}{ Women } \\
\hline & Men & Women & Men & Women & Men & Women & & \\
\hline Depression & 8.7 & $10 \cdot 1$ & $12 \cdot 7$ & $15 \cdot 0$ & $22 \cdot 1$ & $25 \cdot 8$ & $14 \cdot 7$ & $17 \cdot 4$ \\
\hline Digestive disease & $37 \cdot 2$ & 33.8 & $37 \cdot 3$ & $38 \cdot 0$ & $32 \cdot 1$ & $36 \cdot 6$ & $35 \cdot 4$ & $36 \cdot 2$ \\
\hline Musculo-skeletal disorders & $26 \cdot 9$ & $28 \cdot 2$ & $40 \cdot 1$ & $47 \cdot 5$ & $51 \cdot 7$ & $63 \cdot 8$ & $40 \cdot 0$ & $47 \cdot 6$ \\
\hline Obesity & $6 \cdot 8$ & $7 \cdot 0$ & $10 \cdot 9$ & $13 \cdot 7$ & $9 \cdot 4$ & $13 \cdot 0$ & $9 \cdot 1$ & $11 \cdot 5$ \\
\hline Respiratory disease & $22 \cdot 1$ & $23 \cdot 0$ & $27 \cdot 6$ & $21 \cdot 5$ & $42 \cdot 3$ & $31 \cdot 4$ & $31 \cdot 0$ & $25 \cdot 5$ \\
\hline Hip pain & 3.4 & $3 \cdot 8$ & $7 \cdot 9$ & $10 \cdot 5$ & $13 \cdot 2$ & $18 \cdot 4$ & $8 \cdot 3$ & $11 \cdot 3$ \\
\hline Knee pain & $19 \cdot 2$ & $12 \cdot 1$ & $24 \cdot 1$ & $20 \cdot 3$ & $31 \cdot 3$ & $36 \cdot 0$ & $25 \cdot 1$ & 23.5 \\
\hline
\end{tabular}

\section{Depression}

Depression was defined as a score of 8 or more on the depression element of the Hospital Anxiety and Depression Scale. This definition, therefore, includes both depression and borderline depression.

\section{Digestive disorder}

This was defined as a positive response to any of the questions about dyspepsia, heartburn, or indigestion occurring in the previous six months.

\section{Musculo-skeletal disorder}

This was defined as a positive response to any of the questions on joint swelling or painful joints in the absence of injury.

\section{Obesity}

Subjects with a body mass index (weight $(\mathrm{kg}) \times$ height $(\mathrm{m})$ squared/100) of 30 or more were categorised as obese.

\section{Respiratory disease}

Respiratory disease was defined as a positive response to questions on either asthma or chronic bronchitis.

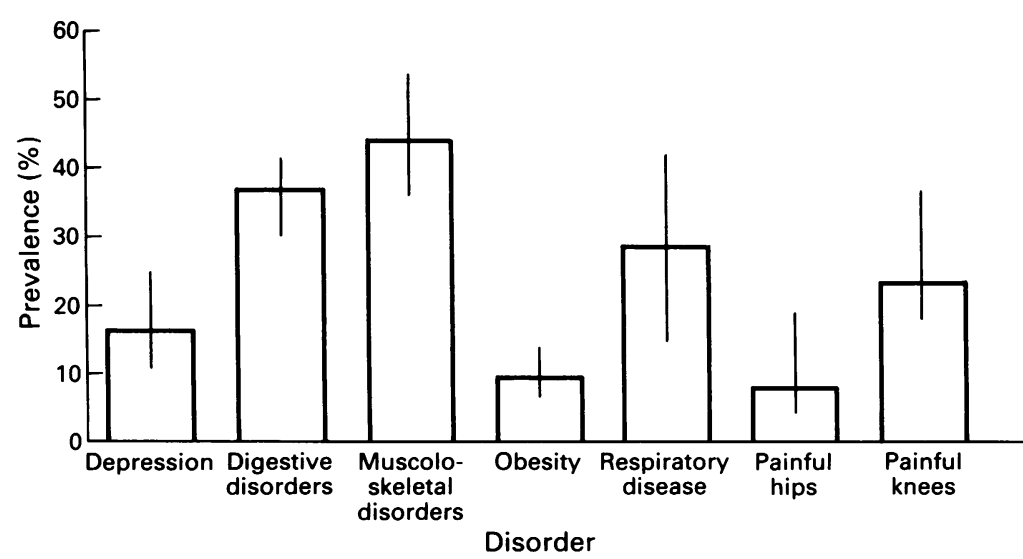

Prevalence of different morbidities in localities in Rotherham (medians and ranges). Median (range) values are as follows: depression 16.2\% (10.7-25.0); digestive disorders $36 \cdot 8 \%(30 \cdot 0-41 \cdot 5)$; musculo-skeletal disorders $44.0 \%$ (35.8-53.3); obesity $9 \cdot 2 \%(6 \cdot 2-13 \cdot 7)$; respiratory disease $28.6 \%(14 \cdot 3-42 \cdot 0)$; painful hips $7.6 \%$ $(4 \cdot 2-18 \cdot 8)$; painful knees $23 \cdot 4 \%(17 \cdot 7-37 \cdot 0)$
Painful hip or knee

Responses to specific questions on painful knees or hips were used directly.

In order to estimate best the prevalence of the morbidities which vary with age and sex in each ward the ward samples were adjusted to reflect the age-sex composition of the underlying ward populations as measured by the 1991 OPCS population estimates. The adjustment was done using six strata of approximately equal size comprising men and women aged 18 to 34 years, 35 to 54 years, and 55 years and over. The adjusted ward sample sizes were kept the same as the actual samples. The agesex specific morbidity prevalences were then applied to the adjusted samples to produce ward estimates of prevalence.

The relationships between the estimated ward prevalences of each of the various morbidities and both the hospital admission rates and the mortality rates were examined using scatterplots and Pearson's correlation coefficient, after testing for violation of the assumptions for regression. Admission rates were calculated using numbers of consultant episodes as the numerator and the $1987 / 8-1991 / 2$ average ward populations as the denominator. Data were not standardised as differences in distribution of sexes and ages between wards should affect both sets of rates equally.

\section{Results}

The total response rate was $78 \%$ (3877 of 5000 ). After exclusion of those who had moved house or died, the response rate became $82 \%$ (3877 of 4752). The response rate before sending the reminder was $63 \%$ (2972 of 4752). Final response rates varied between individual wards from $66.9 \%$ to $89.9 \%$, but in 19 of the 22 wards the proportion who responded was over $75 \%$. The response rates were lower in the more underprivileged wards (correlation coefficients for response rate versus unemployment and Jarman score were -0.74 and -0.84 respectively, $\mathrm{p}<0.01$ )

The variation in the seven types of morbidity in relation to age and sex is shown in table 3. There are appreciable age and sex differences in general, apart from for digestive disease. The age and sex differences for the other conditions are as expected. Because of these differences we decided to adjust the prevalences of all the morbidities to reflect the age-sex composition of the underlying ward populations.

The figure shows a summary of the main results for the estimated prevalence of each of the five main conditions. Musculo-skeletal disorders show a particularly high prevalence, with a median of $44 \%$ among the nine localities. Even in the locality with lowest prevalence it was still over $35 \%$.

The prevalences of depression, respiratory disease, and digestive disorders were all high but again there was considerable variation between localities. Thus, for example, there was a threefold range of respiratory disease prevalence from a minimum of $14 \%$ to a maximum of $42 \%$ in the worst locality. 
Table 4 Correlation coefficients ( $r$ ) for comparisons between prevalence of disease as determined by the morbidity questionnaire and rates of hospital admissions and mortality for specific conditions.

\begin{tabular}{lcc}
\hline Morbidity measure from questionnaire & Admission $r$ & Mortality $r$ \\
\hline Depression & $0 \cdot 52^{*}$ & $\mathrm{NA}$ \\
Digestive system disorders & $0 \cdot 13$ & $0 \cdot 15$ \\
Musculo-skeletal disorders & $0 \cdot 30$ & 0.41 \\
Obesity & $0 \cdot 14$ & $\mathrm{NA}$ \\
Respiratory disease & $0 \cdot 68 \dagger$ & $+0.54 \dagger$ \\
Painful hips & Inverse relation \\
Painful knees & $0 \cdot 14$ & $\mathrm{NA}$ \\
\end{tabular}

$* \mathrm{p}<0.05 ; \dagger \mathrm{p}<0.01$

+ Regression assumption of normality violated. Transformation found a statistically significant inverse relation.

NA $=$ None or insufficient deaths to calculate a correlation coefficient.

\section{CORRELATIONS}

The assumptions for regression were not violated in any of our correlation analyses, apart from hip pain where an inverse relation was found.

Pearson's correlation coefficients between the morbidity measures and hospital use and deaths are shown in table 4 . Over the 22 electoral wards only respiratory disease and depression showed a large enough positive correlation to be statistically significant between admission rates and prevalence as determined by the morbidity survey $(r=0.68$, $p<0.01$ and $r=0.52, p<0.05)$. Even in these cases the size of the correlation coefficients shows that much of the variance in prevalence between wards remains unexplained by differences in the hospital use $\left(\mathrm{r}^{2}=46 \%\right.$ for respiratory disease and $27 \%$ for depression). For the other conditions the correlation coefficients were mostly positive but were too small to be significantly different from zero. In the case of hip replacement rates there was actually a statistically significant inverse relation between the prevalence of hip pain and admission rates. Thus, those wards with high hip replacement rates had low hip pain prevalences and vice versa.

Numbers of deaths over the period studied were too small for correlations between mortality and depression, obesity or joint replacements to be explored. Once again, only for respiratory disease was there a significant positive correlation between morbidity as determined by the survey and mortality rate. This correlation was not as high as that with hospital admission rate.

\section{Discussion}

Researchers from the USA and elsewhere have consistently found that hospital admission and surgical procedure rates generally vary appreciably across geographical areas. ${ }^{18-21}$ The major determinants of these rates were the supply of hospital beds and specialist physicians and surgeons and variations in clinical practice. Ill health has not been found to be a major determinant in the few instances where this has been explicitly studied. ${ }^{21-23}$

A British review addressing the question of whether hospital use can be used as a measure of health need concluded that hospital utilisation data are flawed as a proxy for health needs because of variations in the supply of services and in professional decision making. ${ }^{24}$ Supply of beds is the main determinant of admission rates at both inter-regional and inter-district level. Only for a small number of conditions which are easily diagnosed and for which there is a consensus on treatment (for example, acute myocardial infarction, gastrointestinal haemorrhage) does hospital use seem to relate clearly to morbidity. ${ }^{19}$ By contrast, however, the premise of Royston et al is that at a sufficiently small area level, populations compete for the same exogenous supply of services and that their different relative use of services reflects variations in their relative need. ${ }^{7}$

Not all the conditions considered are likely to lead to hospital admission. A priori it would have been expected that respiratory symptoms and depression would have been more likely to lead to hospital admission with dyspepsia, hip pain, knee pain, and musculo-skeletal disorders less so. It would be unusual for obesity to lead to admission. The results reported here, however, show that at small area level there is poor correlation between the use of hospital services and the prevalence of most of the conditions determined from the morbidity questionnaire. Such surveys, even using validated questions, are themselves only a proxy measure of health but do have the advantage that they sample the whole population, not just those whose ill health comes to light because of contact with the health service. We conclude that, at a small area level, hospital service use is not a particularly useful proxy measure for morbidity, and one that can be used only for a limited range of conditions.

Use of primary care may also reflect morbidity levels. In a study using the Nottingham Health Profile (NHP), ${ }^{90}$ Bucquet and Curtis ${ }^{25}$ found that although social differences in morbidity were not matched by significant social group differences in recent GP consultation behaviour, there were strong statistical associations between consultation and NHP dimensions for physical immobility, social isolation, pain, and emotional distress.

In view of the magnitude of the task of health needs assessment, all routinely available measures that might be a proxy for the health of parts of the population should be examined, and there is a case for greater use of primary care utilisation data. Caution is advised, however, in using hospital service utilisation as a proxy to plan resource allocation without preliminary investigation of its appropriateness for the conditions being studied. The correlation coefficients show that much of the variance between electoral wards remains unexplained and, more importantly, for most conditions hospital service use does not provide even a moderate measure of morbidity. Moreover, there is an indication that, for some conditions, areas with higher prevalence of morbidity actually have lower use of hospital services than those with lower prevalence.

Although both the unemployment rate and Jarman score ${ }^{26}$ have been found to correlate with use of health services, ${ }^{27}$ it cannot be assumed automatically that underlying morbidity bears a similar relationship. Although sociodemographic measures have been sug- 
gested as a proxy measure for local levels of health, ${ }^{27-33}$ our earlier work has shown that measures of social deprivation such as Jarman scores ${ }^{10}$ and unemployment correlate well only with certain specific areas of ill health. ${ }^{34}$

In interpreting the present findings it should be remembered that the response rate varied between electoral wards, although all but three wards had a response rate of over $75 \%$, and that this might have influenced the results. Variation in response rate between social groups was also found in the Whitehall study of health inequalities among civil servants ${ }^{35}$ but is not documented in Curtis's study. ${ }^{33}$ Another important consideration is of the heterogeneity within electoral wards in respect of service utilisation. This may reduce the estimate from a ward-based analysis of the real strength of associations present at a smaller area level. Variability in the use of the private sector in electoral ward populations may partly explain some of the lack of correlations. There are no private inpatient facilities in the local district general hospital, however, and the local population is likely to make limited use of the private sector elsewhere. We cannot be absolutely sure that cases were being ascribed to electoral wards within the Trent Regional Patient Information System with $100 \%$ accuracy. Local hospitals checked all cases for the presence of a valid postcode before dispatching hospital data, however, and Trent region would not accept data with invalid or missing postcodes. Corrections and updates to the regional computerised postcode directory have been continuously made over the past seven years. Planners, researchers, finance staff, and managers have used the patient information system extensively over this period and found no major cause for concern.

Mortality information, although useful as a proxy for morbidity in many circumstances, is also of little value for the common conditions examined here. This is not surprising in view of the small number of deaths associated with these disorders, although their associated morbidity is considerable.

The help of those who agreed for parts of their questionnaires to be used is gratefully acknowledged: Dr R Snaith (Hospital Anxiety and Depression Scale); Mr J Nicholl (Sports Injury Questionnaire); Professor R Jones (Dyspepsia Questionnaire); Professor A Silman (Arthritis Questionnaire); Medical Research Council (Respiratory Symptoms Questionnaire). Rotherham Health Authority funded this research

1 Secretaries of State for Health, Wales, Northern Ireland, and Scotland. Working for patients. London: HMSO, 1989.

2 Committee of Inquiry. Public health in England. London: HMSO, 1988

3 Department of Health. Working for patients. Framework for information systems: the next steps. London: HMSO, 1990.

Resource Allocation Working Party. Sharing resources for health in England. London: HMSO, 1976.

5 Townsend P, Davidson N, Whitehead M. Inequalities in
Health (the Black report). The Health Divide. London: Penguin Books, 1988.

6 NHS Management Board/Department of Health and Socia Security. Review of resource allocation working party formula: final report of the NHS management board. London: mula: final report.

7 Royston GHD, Hurst JW, Lister EG, Stewart PA. Modelling the use of health services by populations of small areas to inform the allocation of central resources to larger regions. Socio-economic Planning Sciences 1992;26:16980

8 Cartwright A. Health surveys. London: King's Fund, 1983 Hunt S, McEwen J, McKenna S. The development of a subjective health indicator. Socio-economic Planning Sciences 1980;2:231-46.

10 Hunt S, McEwen J, McKenna S. The Nottingham Health Profile: subjective health status and medical consultations. Soc Sci Med 1981;15A:221-9.

11 Johnson IS, Coyne A-M, Milner PC, et al. A profile of health care and disease in Sheffeld. Sheffield: Sheffield Health Authority, 1986

12 Zigmond AS, Snaith P. The hospital anxiety and depression scale. Acta Psychiat Scand 1983;67:361-70.

13 Jones R, Lydyeard S. Prevalence of symptoms of dyspepsia in the community. BMF 1989;298:30-2.

14 Nicholl JP, Coleman P, Williams BT. A national study of the epidemiology of exercise related illness and injury. A report to the Sports Council of England. Sheffield: Medical Care Research Unit, 1992.

15 Medical Research Council's Committee on Environmental and Occupational Health. Questionnaire on respirator symptoms. London: Medical Research Council, 1986.

16 World Health Organization. Manual of the international statistical classification of disease, inquiries and causes of death. 9th rev. Geneva: World Health Organization, 1977.

17 Office of Population Censuses and Surveys. Tabular list of the classification of surgical operations and procedures. 4 th rev. London: HMSO, 1990.

18 Wennberg J, Gittelsohn A. Small area variations in health care delivery. Science 1973;182:1102-8.

19 Wennberg JE, Freeman JL, Shelton RM, Bubolz TA. Are hospital services rationed in New Haven or over-utilised in Boston? Lancet 1987; i:1185-9.

20 McPherson $K$, Wennberg JE, Hovind OB, Clifford $P$ Small area variations in the use of common surgical procedures: an international comparison of New England, procedures: an international comparison of New England,

21 Roos NP, Roos LL. Surgical rate variations: do they reflect the health or socio-economic characteristics of the population? Med Care 1982;20:945-58.

22 Wennberg JE. Population illness rates do not explain population hospitalisation rates: a comment on Mark Blumberg's thesis that morbidity adjusters are needed to inter pret small area variations. Med Care 1987;25:354-9.

23 Connell FA, Blide LA, Hanken MA. Clinical correlates of small area variations in population-based admission rates for diabetes. Med Care 1984;22:939-49.

24 Morgan M, Mays N, Holland WH. Can hospital use be a measure of need for health care? I Epidemiol Community Health 1987;41:269-74.

25 Bucquet D, Curtis S. Socio-demographic variation in perceived illness and the use of primary care: the value of community service data for primary health care planning. Soc Sci Med 1986;7:737-44.

26 Jarman B. Identification of underprivileged areas. BMF 1983;286:1705-9.

27 Campbell DA, Radford JMC, Burton P. Unemployment rates: an equivalent to the Jarman index? $B M^{9}$ 1991:303:750-5.

28 Franks PJ, Adamson C, Bulpitt PF, Bulpitt CJ. Stroke death and unemployment in London. $\mathcal{F}$ Epidemiol Community Health 1991;45:16-18.

29 Johnson IS, Milner PC. Is the Jarman score better than social class at assessing the need for prevention and
s. Is social class at assessing the need for
primary care? Fam Pract 1988;5:105-10.

30 Charlton JRH, Lakhani A. Is the Jarman underprivileged area score valid? $B M \mathcal{F}$ 1985;290:1714-16.

31 Carstairs V, Morris R. Deprivation, mortality and resource use. Community Med 1989;11:364-72.

32 Mays N, Chinn S. Relation between all cause standardised mortality ratios and two indices of deprivation at regional and district level in England. 7 Epidemiol Community Health 1989;43:191-9.

33 Curtis S. Use of survey data and small areas statistics to assess the link between individual morbidity and neighbourhood deprivation. 7 Epidemiol Community Health 1990;44:62-8.

34 Payne JN, Coy J, Patterson S, Milner PC. Are deprivation indicators a proxy for morbidity? $\mathcal{F}$ Public Health Med 1993;15:161-70.

35 Marmot MG, Davey Smith G, Stansfield S, et al. Health inequalities among British civil servants: the Whitehall II study. Lancet 1991;337:1387-93. 